\title{
SSPA Equipment Engineering Feasibility Report
}

\author{
N.E. Woolstenhulme \\ C.R. Clark
}

September 2011

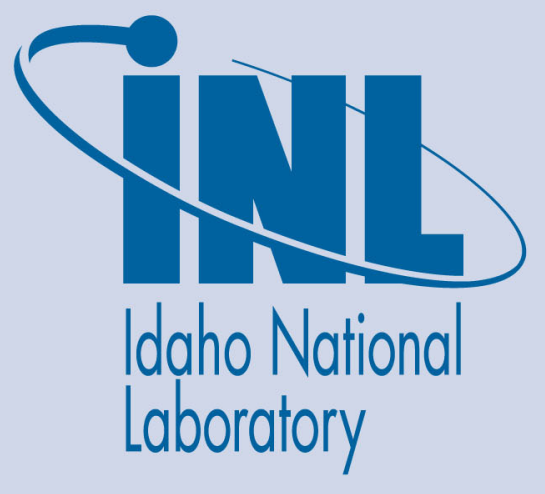

The INL is a U.S. Department of Energy National Laboratory operated by Battelle Energy Alliance 


\section{DISCLAIMER}

This information was prepared as an account of work sponsored by an agency of the U.S. Government. Neither the U.S. Government nor any agency thereof, nor any of their employees, makes any warranty, expressed or implied, or assumes any legal liability or responsibility for the accuracy, completeness, or usefulness, of any information, apparatus, product, or process disclosed, or represents that its use would not infringe privately owned rights. References herein to any specific commercial product, process, or service by trade name, trade mark, manufacturer, or otherwise, does not necessarily constitute or imply its endorsement, recommendation, or favoring by the U.S. Government or any agency thereof. The views and opinions of authors expressed herein do not necessarily state or reflect those of the U.S. Government or any agency thereof. 


\title{
SSPA Equipment Engineering Feasibility Report
}

\author{
N.E. Woolstenhulme \\ C.R. Clark
}

September 2011

Idaho National Laboratory Idaho Falls, Idaho 83415

http://www.inl.gov

\author{
Prepared for the
}

U.S. Department of Energy

Office of National Nuclear Security Administration

Under DOE Idaho Operations Office

Contract DE-AC07-05ID14517 


\title{
SSPA Equipment Engineering Feasibility Report
}

\author{
INL/EXT-11-23173
}

N.E. Woolstenhulme

C.R. Clark

Approved by:

N.E. Woolstenhulme

C.R. Clark

A.M. Phillips

H.W. Glunz

M.K. Meyer

D.M. Wachs

\begin{tabular}{cc}
\hline Date \\
\hline Date \\
\hline Date \\
\hline Date \\
\hline Date \\
\hline Date
\end{tabular}




\section{CONTENTS}

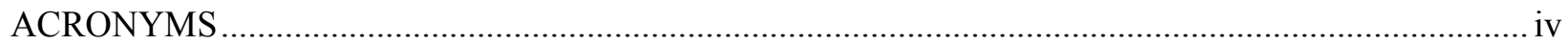

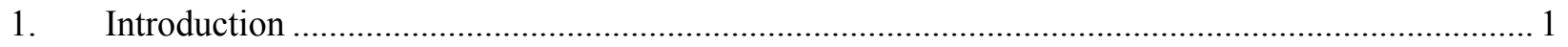

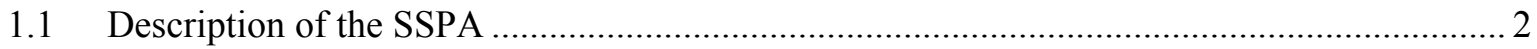

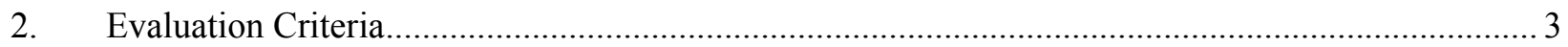

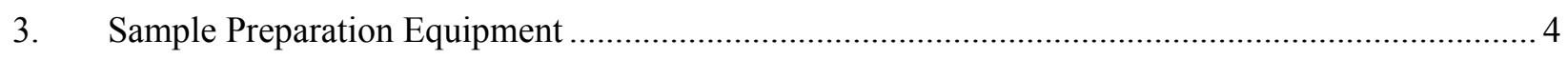

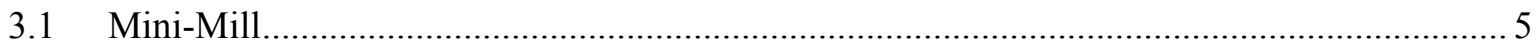

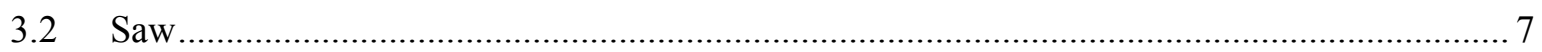

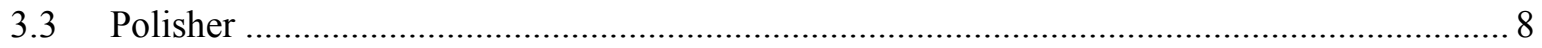

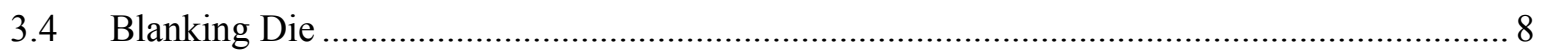

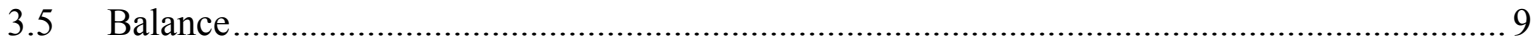

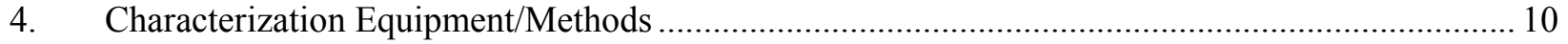

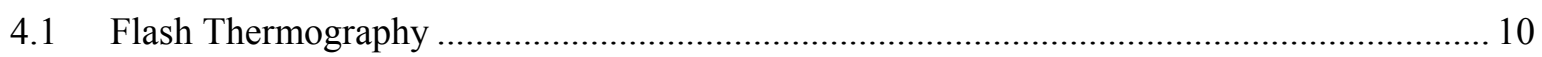

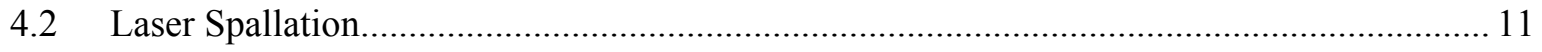

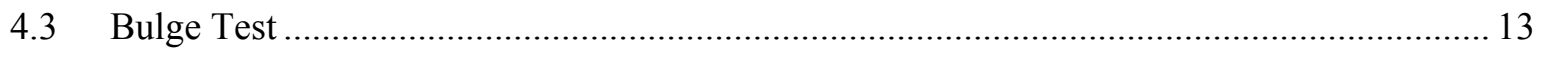

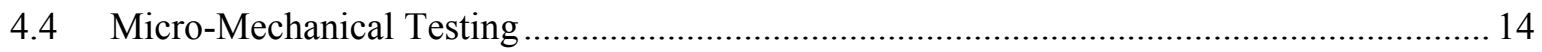

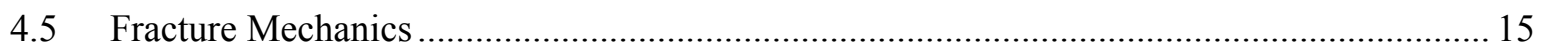

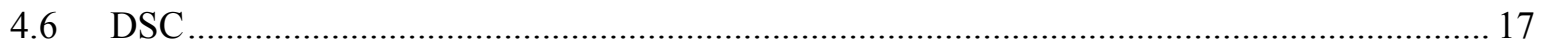

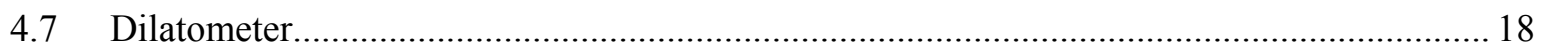

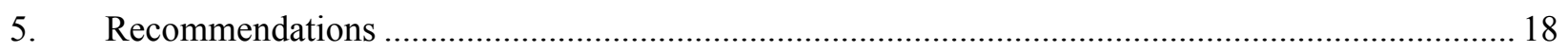

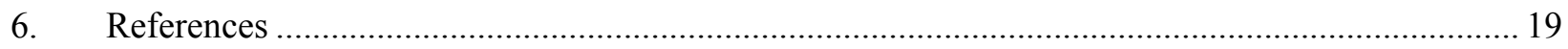




\section{ACRONYMS}

CNC Computer Numeric Control

DCB Dual Cantilever Beam

DSC Differential Scanning Calorimeter

EML Electron Microscopy Laboratory

FD Fuel Development

FIB Focused Ion Beam

GTRI Global Threat Reduction Initiative

HEU Highly Enriched Uranium

HFEF Hot Fuel Examination Facility

HIP Hot Isostatic Press

INL Idaho National Laboratory

IR Infra-Red

LANL Los Alamos National Laboratory

LEU Low Enriched Uranium

MFC Materials and Fuel Complex

ORNL Oak Ridge National Laboratory

PIE Post-Irradiation Examination

RERTR Reduced Enrichment for Research and Test Reactors

SSPA Shielded Sample Preparation Area 


\section{SSPA Equipment Engineering Feasibility Report}

\section{Introduction}

The Fuel Development (FD) pillar of the Reduced Enrichment for Research and Test Reactors (RERTR) program under the Global Threat Reduction Initiative (GTRI) is responsible for maturing the fuel technology necessary to convert research and test reactors from fuels containing Highly Enriched Uranium (HEU) to Low Enriched Uranium (LEU, defined as $\left.<20 \mathrm{wt} \%{ }^{235} \mathrm{U}\right){ }^{[1]}$. Some of these reactors will require fuel with very high uranium density to convert ${ }^{[2]}$. These high uranium densities are not achievable with traditional dispersion fuels. As a result, FD is primarily focused on maturing the technology of the uranium-molybdenum monolithic base fuel system. The base monolithic fuel design consists of uranium-10 wt $\%$ molybdenum alloy (U-10Mo) in the form of a monolithic foil, with thin zirconium interlayers, clad in aluminum by hot isostatic press (HIP) ${ }^{[3]}$ as seen in Figure 1.

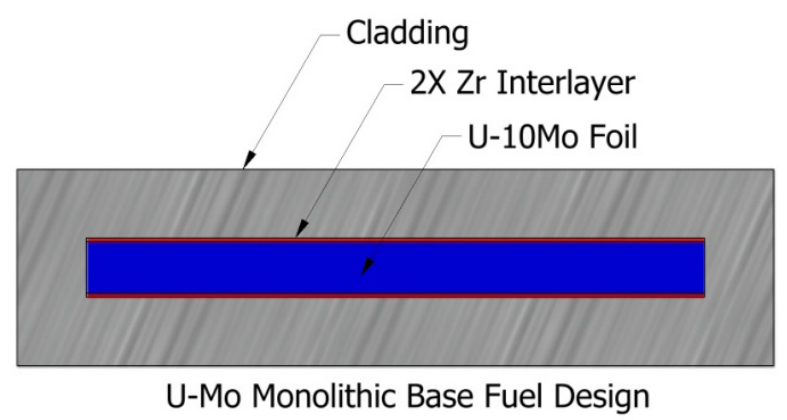

Figure 1: U-Mo Monolithic Base Fuel Design

The reactors which will use this fuel have established safety bases for their current HEU dispersion fuels. Often, these safety bases come from analyses which utilize material properties of both the fuel material and overall fuel plate system. Conversion of these reactors will require safety analyses comparable to the suite currently available for the HEU fuels, or analyses showing that the performance of the new fuel is bound by the analyses performed for the existing fuel. Additionally, the monolithic fuel system employs new fuel meat materials and represents a fairly substantial departure from the existing dispersion fuel designs. This requires new data to be gathered in order to cultivate a proper understanding of the fuel's behavior and to enable accurate safety analyses. In several cases these data sets must include both fresh-fuel and postirradiated data. Several data sets remain to be obtained for the post-irradiated fuel including:

1) Specific Heat Capacity

2) Coefficient of Thermal Expansion

3) Thermal Diffusivity (bulk measurement)

4) Interfacial Bond Strength

In response to a demanding reactor conversion schedule, construction of the Shielded Sample Preparation Area (SSPA) was initiated in 2010 to augment the existing capabilities of the Hot Fuel Examination Facility (HFEF). While HFEF is and will remain the workhorse for post irradiation sample preparation, there is currently a large backlog of Post-Irradiation Examination (PIE) experiments caused by numerous competing projects (this backlog is expected to continue for the foreseeable future). HFEF, in its present configuration also lacks the ability to prepare 
samples suitable for several of the tests that have been identified for the successful conclusion of the RERTR program; these samples require fine detail machining of irradiated fuel plates (see the Characterization section for specifics).

The SSPA is to be installed in a to-be-constructed annex to the Electron Microscopy Laboratory (EML) located in the Materials and Fuel Complex (MFC) of the Idaho National Laboratory (INL). The purpose of this report is to evaluate the feasibility of modifying, installing, and operating equipment in the SSPA to gather the data sets discussed above.

\subsection{Description of the SSPA}

The SSPA consists of two lead-shielded cells, each approximately 40" X 40" internal floor footprint, interconnected with a sliding tray transfer port. Two remote manipulators exist in each cell. Each cell is viewable through a leaded glass window. These windows hinge out of the way to enable access through the front of each cell. Each cell contains a penetration/feed-through panel, power receptacles, and a bag-out port ${ }^{[4]}$. The SSPA was fabricated primarily in calendar year 2011 by I. P. Systems Inc. and delivered to the INL in August of 2011. A rendering of the SSPA can be seen in Figure 2.
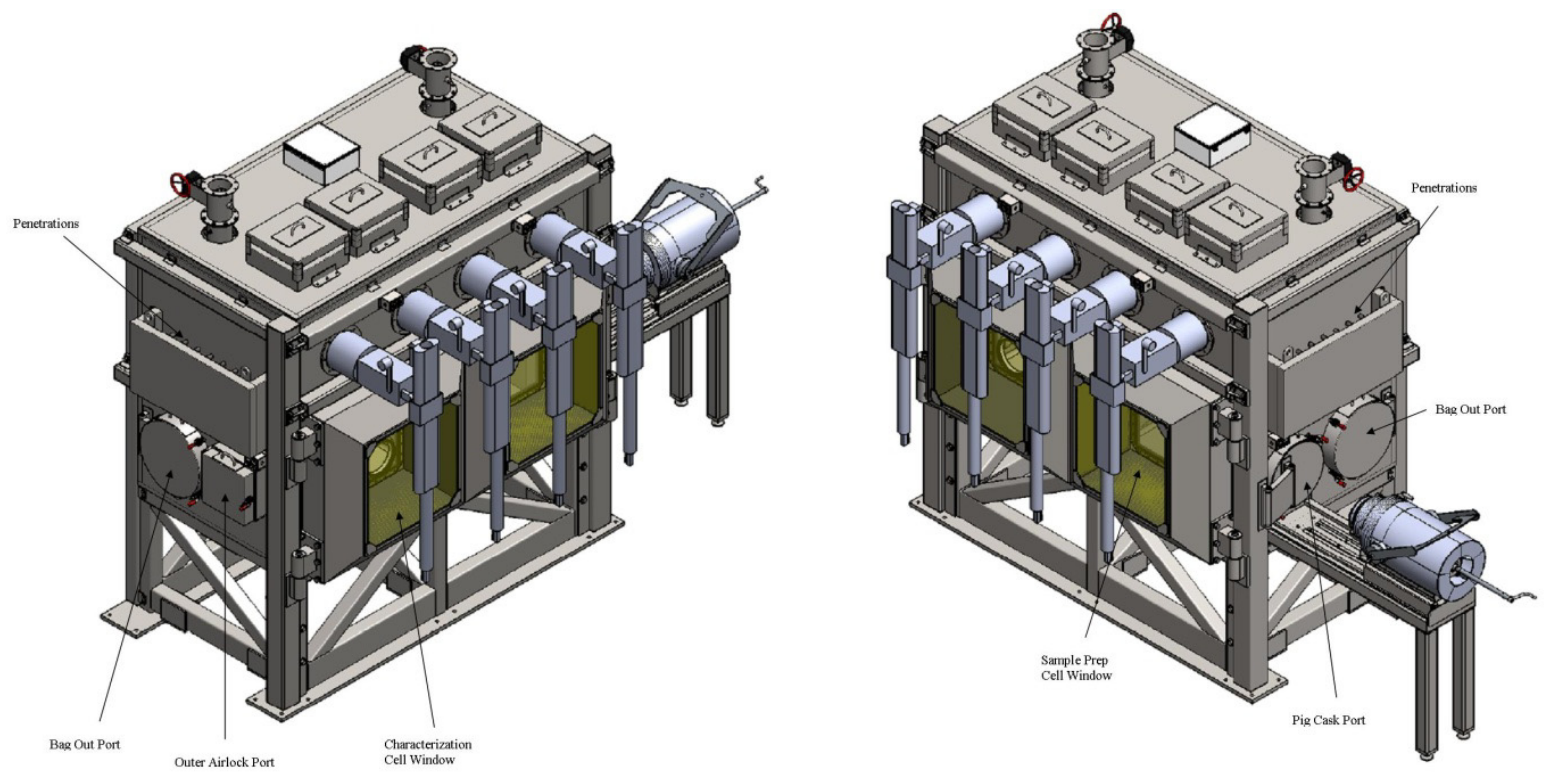

Figure 2: SSPA Rendering

The right hand cell will house a sample preparation area and contains a small electric crane for hoisting heavier equipment. Irradiated samples may be transferred into the sample preparation cell via a small, shielded "Pig" cask designed to accommodate transfers contained in a $500 \mathrm{ml}$ Nalgene bottle. As this cell will perform mass removal processes on irradiated samples, it is anticipated that contamination levels will eventually become significant. The equipment installed in this cell will likely remain in this cell for the lifetime of the equipment.

The left hand cell is referred to as the characterization cell and purposed for performance of the tests required to gather the data sets discussed in section 1 of this report. Those samples which are prepared for data gathering purposes in the sample preparation cell may be transferred to the 
characterization cell through the sliding tray transfer port. Additionally, the characterization cell window may be hinged out of the way to provide access to glove ports. Compared to the sample preparation cell, it is anticipated that contamination levels will remain much lower in the characterization cell. The floor space in the characterization cell will be more "transient" than that of the sample preparation cell in that each piece of equipment will be installed, data will be gathered using it, and then removed to make room for the next piece(s) of equipment and series of tests.

\section{Evaluation Criteria}

The purpose of this report is to evaluate the overall feasibility of potential SSPA equipment in terms of three main categories:

- Modification (modifying the equipment for use in the SSPA)

- Availability of equipment/materials

- Off-the-shelf vs. custom fabrication

- Remotization modifications

- Installation (installing the equipment in the SSPA)

- Transfer into the cell through various paths

- Footprint

- Feedthroughs/penetrations

- Operation (Operating the equipment in the SSPA)

- Maintenance, repair, troubleshooting

- Preparing suitable samples

- Remote operation, calibrating and gathering data

The feasibility related to each of these three categories is qualitatively ranked into one of three classifications:

- Simple

- Well demonstrated in hot cell or similar environment

- No anticipated major technical/logistic issues

- High level of confidence in cost/schedule estimates

- Moderate

- Proof-of-concept demonstrated in applicable configurations

- A small number of uncertainties and unresolved issues exist

- Moderate confidence in cost/schedule estimates

- Difficult

- Theoretical or non-prototypic demonstration only

- Several unknowns and/or complex technical issues exist

- Difficult to provide accurate cost/schedule estimates

The feasibility analysis is qualitative only and based primarily on existing knowledge and best engineering judgment. This report does not provide feasibility classification for whether the proposed equipment/method will accurately measure the desired data. Rather, this report 
evaluates whether the equipment/method is feasible to use in the SSPA environment. It is also beyond the scope of this report to determine the feasibility of performing these tests in another location (primarily HFEF).

\section{Sample Preparation Equipment}

As mentioned previously, the bulk of the equipment in the sample preparation cell of the SSPA is intended to be installed in one initial campaign and to remain in the cell for the lifetime of the equipment. The primary pieces of equipment considered in this report are:
1) Mini-Mill
2) Saw
3) Polisher
4) Blanking Die
5) Balance

While each above listed item is discussed in greater detail in following sections, part of the overall feasibility was to obtain equipment footprints and evaluate whether all the equipment was able to simultaneously "fit" into the cell as seen in Figure 3. 


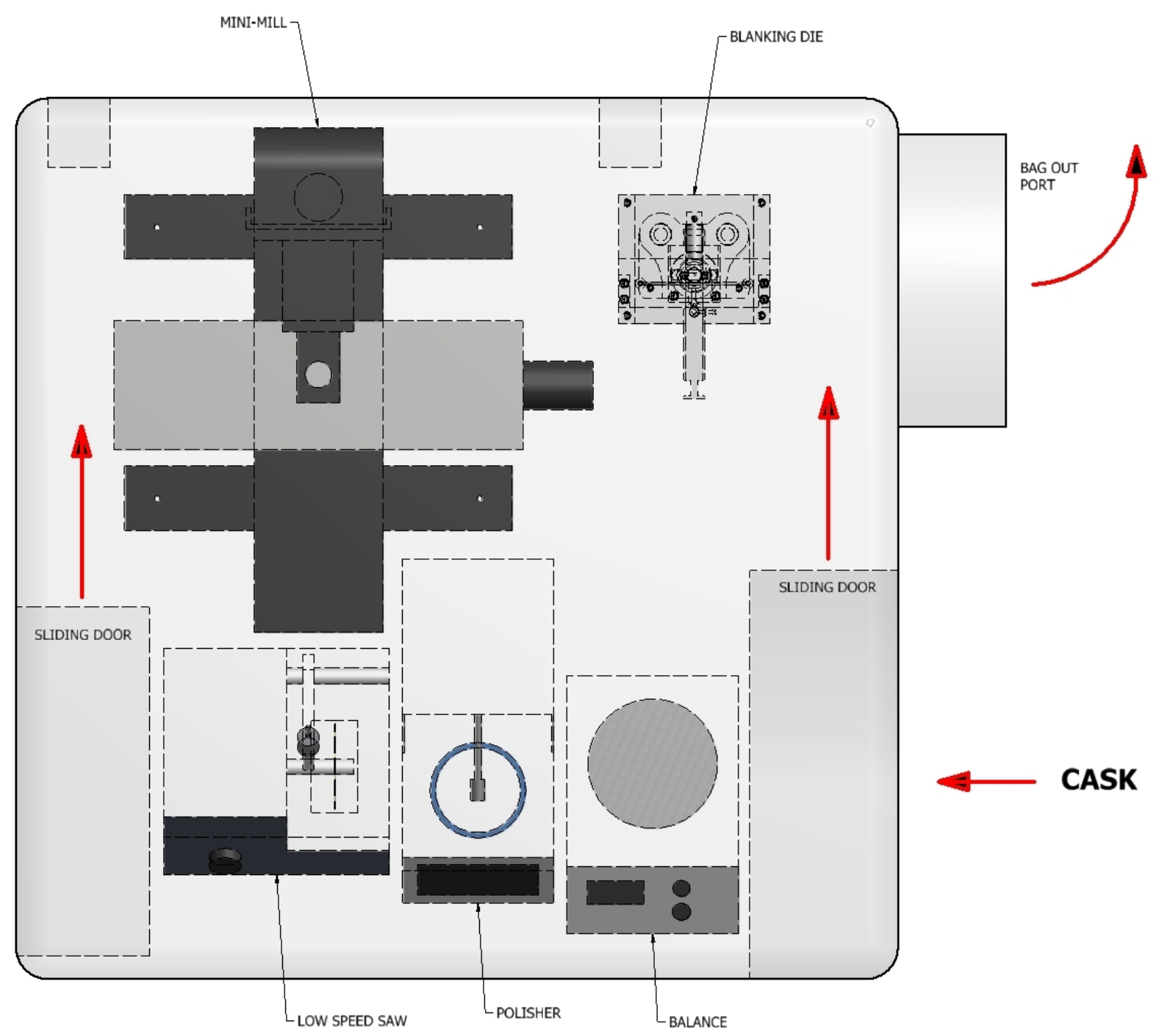

Figure 3: SSPA Sample Preparation Cell Example Layout

Other pieces of equipment are also intended for use in the SSPA, but are not specifically discussed in this report as they are smaller ancillary items which do not directly pertain to sample preparation. These may include items such as cameras, balances, beakers, epoxies, and other various tools. It is also anticipated that the manipulators and crane can be used to hoist these items onto adjustable shelving against the back wall of the sample preparation cell when not in use. Overall, it was determined that "fitting" all of the sample preparation equipment in the SSPA is feasible.

\subsection{Mini-Mill}

The Mini-mill selected for the SSPA was originally procured for use in the HFEF, but was later repurposed for use in the SSPA. It is a Mini-Mill/3 model from the Minitech Machinery Corporation (a similar model is seen in Figure 4). The true value/need of this equipment is the ability to fabricate complex geometry samples that are required for various characterization processes. Several of the characterization methods included in this report will require the fine detail that this equipment will provide. 


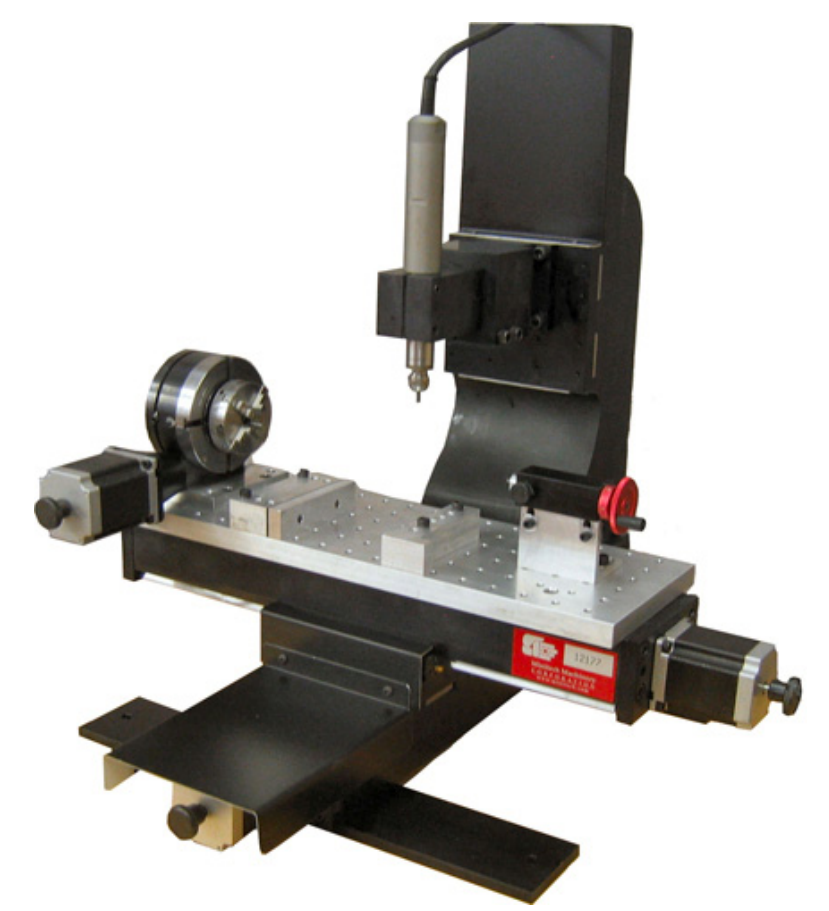

Figure 4: Unmodified Mini-Mill/3 (photo reference [5]). The rotational axis (on the left side of the work table) was not procured.

This model is a Computer Numeric Control (CNC) full 3-axis mill with X and Y travels of 12" and 9", respectively. This machine is intended for use in preparing more complex irradiated sample preparation including tensile test specimens, bulge test specimens, fracture mechanic samples, and other various shapes as achievable with modern 3 axis milling. The travel range of this machine far exceeds the largest irradiated sample sizes that may be prepared in the SSPA.

Modification feasibility is classified as Moderate. Although the item is off-the-shelf and currently in possession, experts in the field of equipment remotization have stated that this machine will require fabrication of several "manipulator friendly" features to enable tooling exchanges, specimen fixturing, etc. Milling machines have been successfully remotized for use in HFEF.

Installation feasibility is classified as Moderate. This machine requires feedthroughs including compressed air for the spindle bearings, motor control cables, and outlet power for motor operation. These utilities/penetrations either already exist in the SSPA, or can be added through the main penetration panel. The mini-mill represents the largest piece of equipment to be placed in the sample preparation cell and cannot be placed in the SSPA through any port except the main viewing window when opened. Consequently, the installation of the mini-mill is only classified as moderate based on the assumption that it can be installed into the SSPA during the initial installation campaign; prior to irradiated samples or contamination becoming present in the sample preparation cell. If modifications to the mini-mill are not completed in time to enable installation in the initial "clean" campaign, the feasibility of installing the mini-mill will become more difficult.

Operation feasibility is classified as Moderate. While this machine would be modified so that routine maintenance items could be performed remotely (e.g. tool replacement), other non- 
anticipated maintenance items could prove difficult (e.g. replacement of table drive motor). This feasibility classification is given on the following bases:

- Unlike most of the sample preparation equipment discussed in following sections, this mini-mill has not been demonstrated in a hot cell environment.

- It will be installed in the sample preparation cell, where contamination will likely to make removal of the mini-mill for operational maintenance difficult as is can only be removed through the main window.

\subsection{Saw}

The saw selected for use in the SSPA sample preparation cell is a Buehler IsoMet Low Speed Saw as seen in Figure 5. This saw will be used for simple sample preparations where rotary saw cuts are sufficient. Primarily, this saw will be used to remove small samples from irradiated fuel plate specimens for the production of microscopy mounts.

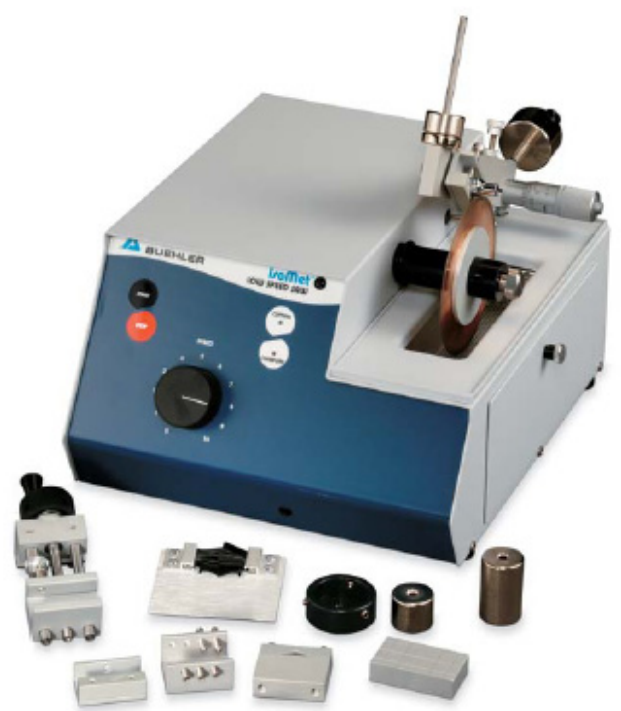

Figure 5: Unmodified IsoMet Low Speed Saw (photo reference [7])

Modification feasibility is classified as Simple. This same saw model has been remotized successfully for use in HFEF.

Installation feasibility is classified as Simple. This same saw model has been installed successfully in HFEF.

Operation feasibility is classified as Simple. This same saw model has been operated and used successfully in HFEF. Past experience with this saw has already produced designs which enable remote maintenance and sample cutting operations. 


\subsection{Polisher}

The polisher selected for use in the SSPA sample preparation cell will likely be a Buehler MiniMet 1000 model as seen in Figure 6. This polisher will be used for polishing of microscopy mounts.

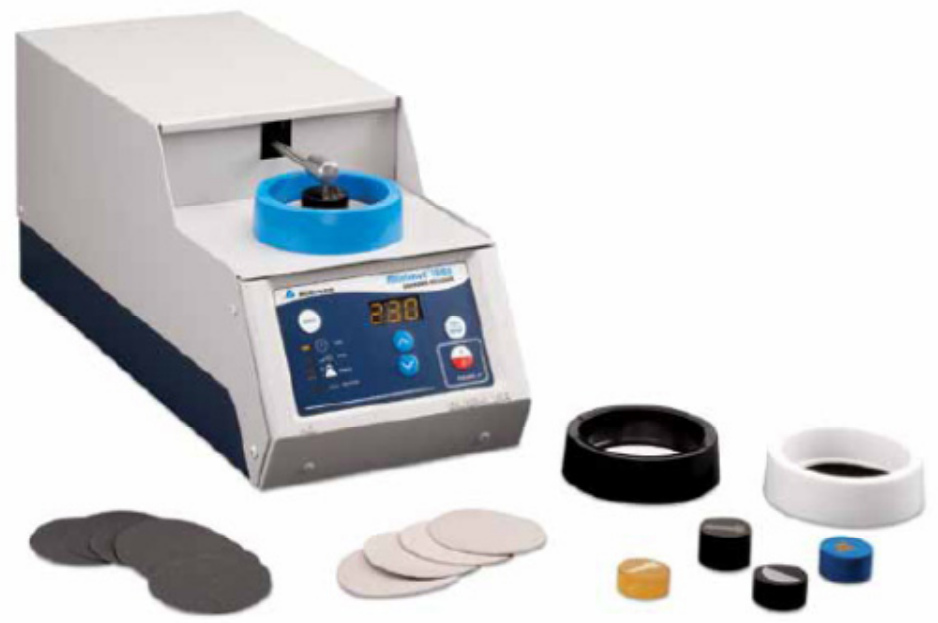

Figure 6: Unmodified MiniMet 1000 (photo reference [8])

Modification feasibility is classified as Simple. This same polisher model has been successfully modified for remote use in HFEF.

Installation feasibility is classified as Simple. This polisher will require a penetration for the remotized control unit cable only.

Operation feasibility is classified as Simple. Once modified for remote operation and "manipulator friendly" sample loading, the overall operation of this polisher will be simple.

\subsection{Blanking Die}

The blanking die will be used for blanking, or punching, sample shapes such as discs and tensile test specimens. The blanking die apparatus will likely be based a similar unit which was recently installed in the HFEF. A rendering of this device is seen in Figure 7. 


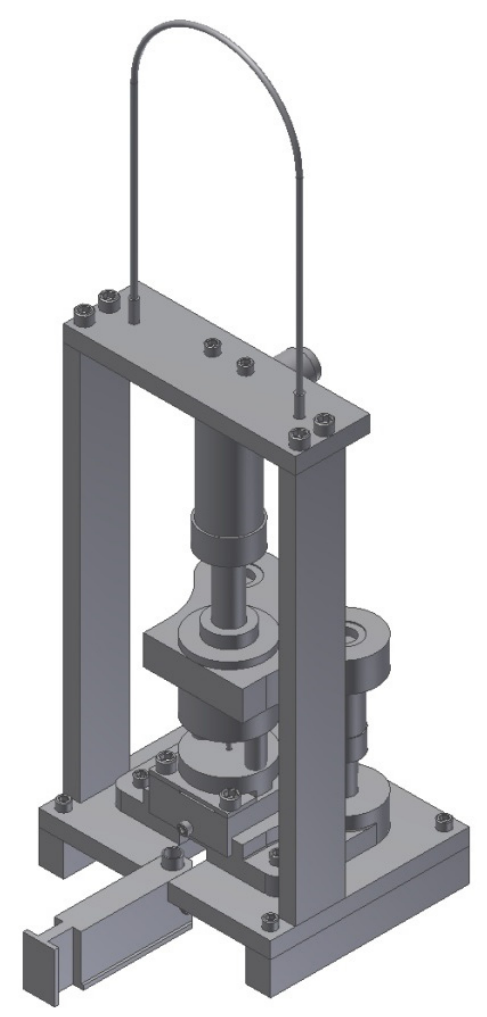

Figure 7: HFEF Blanking Die "Punch"

Modification feasibility is classified as Simple. While this is a unique design, it closely mimics previous systems that have operated in other hot cells at MFC. The blanking die will be a custom fabricated design, where some of the components may be purchased as off-the-shelf items such as the die-set and hydraulic components.

Installation feasibility is classified as Simple. This blanking die will require a penetration for the remotized control unit cable only.

Operation feasibility is classified as Simple. Once modified for remote operation and "manipulator friendly" sample loading, the overall operation of this blanking die will likely be simple.

\subsection{Balance}

The balance selected for use in the SSPA sample preparation cell will be an analytical balance with high precision ( $0.0001 \mathrm{~g}$ resolution) that is modified for operational control outside the hot cell. No specific balance has been selected at this point however this is a standard item that has been used in cell numerous times.

Modification feasibility is classified as Simple. Balances are routinely modified for remote use in HFEF.

Installation feasibility is classified as Simple. The balance will require a penetration for the remotized control unit cable only. 
Operation feasibility is classified as Simple. Once modified for remote operation and "manipulator friendly" sample loading, the overall operation of this balance will be simple.

\section{Characterization Equipment/Methods}

As explained in section 1.1, the equipment in the characterization cell is intended to be installed in the SSPA, used to gather the desired data, and then removed from the cell to make room for the next series of tests/equipment ${ }^{\mathrm{a}}$.

\subsection{Flash Thermography}

Flash thermography exposes one side of a fuel plate specimen to a brief heat input via a flash bulb while simultaneously capturing the time dependent response of the opposite side of the fuel plate specimen with an Infra-Red (IR) camera as seen in Figure 8.

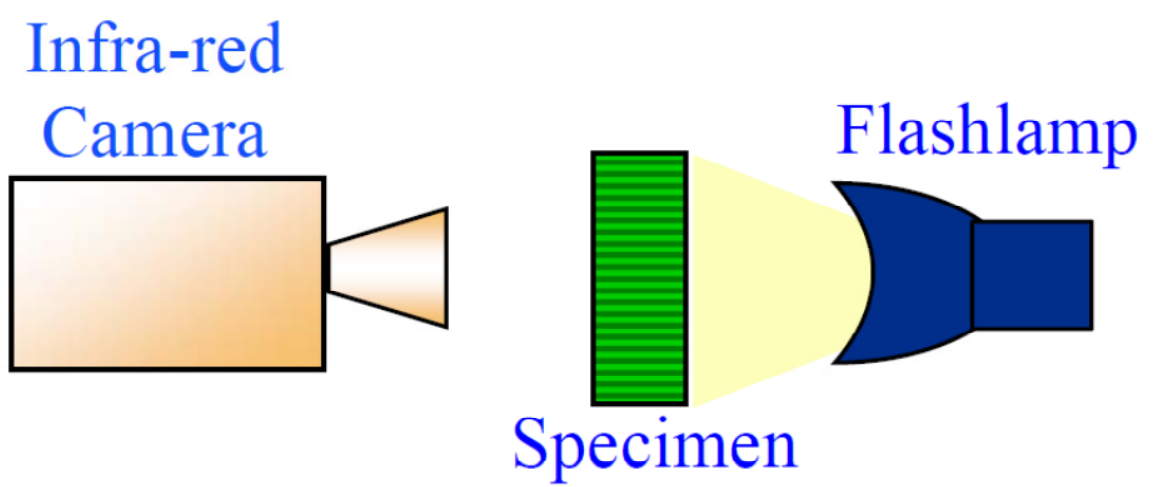

Figure 8: Flash Thermography Setup (figure reference [9])

Due to its ability to characterize areas of low thermal conductivity (such as voids or debonds), this method has been investigated for use in non-destructive examination of the bond quality of unirradiated fuel plates ${ }^{[9]}$. However, this method is intended for use in the hot cell environment to characterize thermal diffusivity properties of the irradiated fuel. A FLIR Systems model SC8000 IR camera (as seen in Figure 9) is currently available at INL for this testing.

\footnotetext{
${ }^{a}$ Unlike the sample preparation cell, the size of the equipment under consideration for operation in the characterization cell will not allow for installation of several different instruments
} 


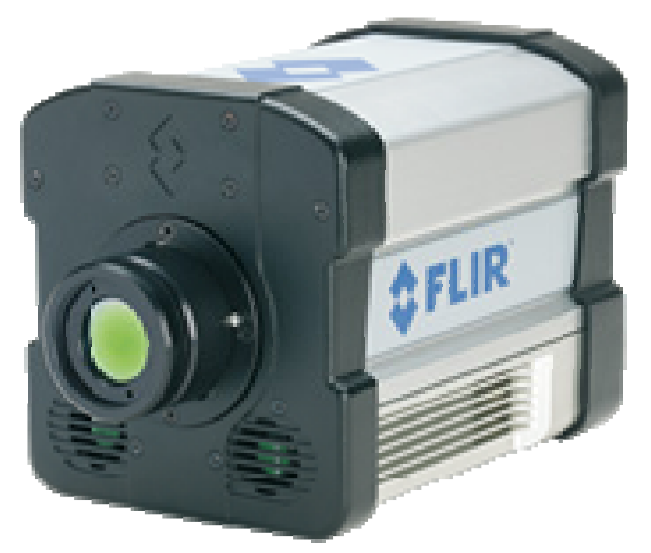

Figure 9: FLIR Systems SC Series IR Camera (photo reference [10])

This system can gather data on whole and/or simple sections of fuel plate specimens. With little sample preparation required, this system is being considered for installation in the SSPA or HFEF. In both cases the IR camera will be located outside of the hot cell and will record the specimen's IR response through an image transmitting devices such as optical fibers or periscope.

Modification feasibility is classified as Moderate. The IR camera, high speed computer, and other peripherals will operate outside of the hot cell in an unmodified state. A straightforward specimen holder will need to be fabricated to fixture the specimen and flash lamp. This specimen holder could possibly be used dually for flash thermography and laser spallation (see section 4.2) The only real technological challenge is how to integrate the system that exists on either side of a shielded cell barrier which is beyond the present experience at the INL.

Installation feasibility is classified as Simple. Investigations into a shielded plug with a simple internal periscope, designed to replace the bag out port of the characterization cell, indicate that this will be straightforward. This periscope could possibly be used dually for flash thermography and laser spallation (see section 4.2). A simple feedthrough will be needed for flash lamp power cable. Although the use of optical fibers in lieu of periscopes is being investigated in terms of transmission quality, such would necessitate an additional feedthrough which is likely to be no more difficult than a normal cable type feed through.

Operation feasibility is classified as Simple. The majority of the equipment will be operated outside of the hot cell. In cell operations will involve fixturing of specimens using a simple, mechanical apparatus. The use of thermography in a hot cell environment has been demonstrated by Oak Ridge National Laboratory ${ }^{[11]}$.

\subsection{Laser Spallation}

Laser spallation exposes a fuel plate specimen to a localized, rapid, and intense heat input using a laser pulse. This, in turn, causes mechanical stresses at the monolithic foil to aluminum cladding bonding interface which can cause a small delamination. An interferometer can be used as a non- 
contact method to detect whether a laser pulse, of a given intensity, has caused delamination. This method, in conjunction with finite element modeling, can be used to quantify cladding-tofoil bond strength of irradiated specimens.

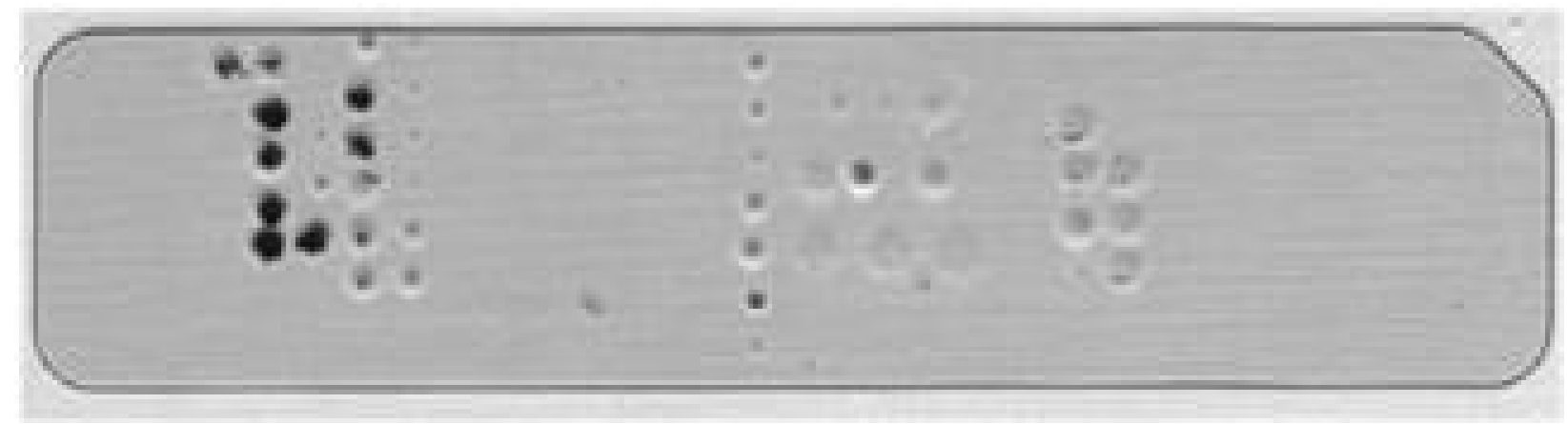

Figure 10: Ultrasonic Image of Laser Spallation Induced Delaminations (figure reference [13])

Like thermography, this system can gather data on whole and/or simple sections of fuel plate specimens. With little sample preparation required, this system is being considered for installation in the SSPA. The laser and interferometer would be located outside of the hot cell and use optical transmission devices such as a periscope or fiber optics.

Modification feasibility is classified as Simple. The laser, interferometer, and other peripherals will operate outside of the hot cell in an unmodified state. A straightforward specimen holder will need to be fabricated to fixture the specimen and locate laser delivery systems. This specimen holder could possibly be used dually for flash thermography (see section 4.1) and laser spallation.

Installation feasibility is classified as Simple. Investigations into a shielded plug with a simple internal periscope, designed to replace the bag out port of the characterization cell, indicate that this will be straightforward. This periscope could possibly be used dually for flash thermography (see section 4.1) and laser spallation.

The use of fiber optics has also been proposed as a transition method and while there is no reason this won't work, the additional unknowns introduced by using this technology (damage to the lines by the laser, alignment issues, and the implementation of a less common method) move the installation to a Moderate status ${ }^{\mathrm{b}}$.

Although the use of optical fibers in lieu of periscopes is being investigated in terms of transmission quality, such would necessitate a feedthrough which is likely to be no more difficult than a normal cable type feed through.

Operation feasibility is classified as Simple. The majority of the equipment will be operated outside of the hot cell. In cell operations will involve fixturing of specimens using a simple, mechanical apparatus.

\footnotetext{
${ }^{\mathrm{b}}$ Fiber optics may offer advantages that would make it a preferred technology in HFEF
} 


\subsection{Bulge Test}

The bulge test method is under development at Los Alamos National Laboratory (LANL) and uses pressure to produce delaminations across the cladding-to-foil interface. The technique involves drilling a precision depth flat-bottom hole through one side of cladding and the monolithic foil. This cavity is pressurized until a delamination occurs and the cladding bulges up in a circular blister. The boundary of the bulge which results can be used to quantify interfacial bond strength. Bugle tests schematics and prototype test apparatus can be seen in Figure 11 and Figure 12, respectively.
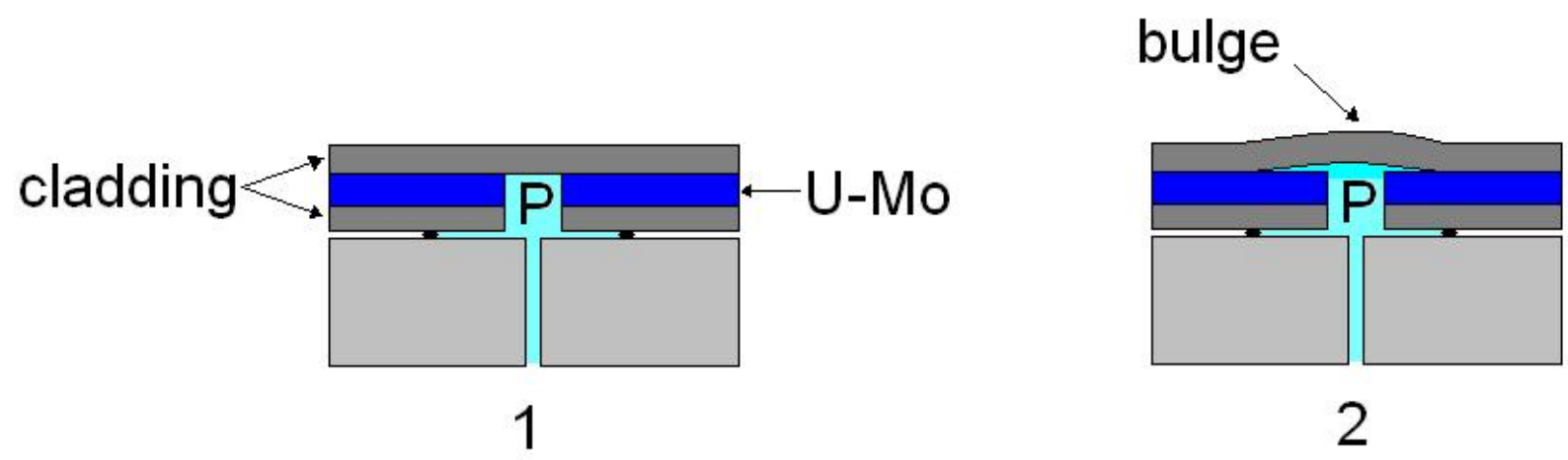

Figure 11: Bulge Test Schematic
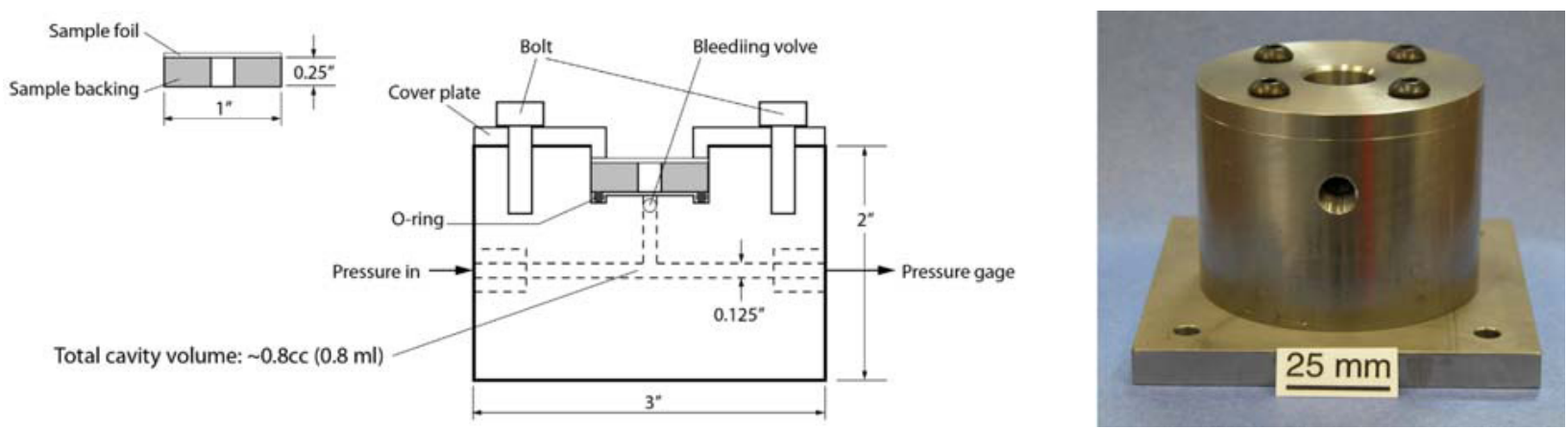

Figure 12: LANL Prototype Bulge Test Apparatus (figure reference [12])

Modification feasibility is classified as Simple. The bulge test apparatus is a simple device for which design and fabrication for use in a hot cell should be straightforward.

Installation feasibility is classified as Moderate. The bulge test apparatus can likely be designed to pass through the SSPA's airlock ports. The bulge test will require a feedthrough for compressed gas. It is expected that the system will need to accommodate at least 300 psig as this was the pressure required to fail LANL adhesive bonded specimens ${ }^{[14]}$. This will likely result in a classification of "high hazard pressure system"; triggering more rigorous safety reviews and protocols, particularly for use in a hot cell environment ${ }^{[15]}$.

Operation feasibility is classified as Difficult. This is considered difficult to perform due primarily to the complexity of sample preparation. Precise depth of the initial hole is crucial to this test, which may prove challenging as fuel foil location can vary somewhat within the 
thickness of the fuel plate. Production of samples suitable for this testing is foreseen to require the mini mill be operational in the sample preparation area.

\subsection{Micro-Mechanical Testing}

Development of nano and micro-mechanical testing is under development at LANL. These techniques can be used to measure a variety of mechanical properties and behavior including hardness, elastic modulus, ductility, and interfacial bond strength. Example nano-sized mechanical test specimens can be seen in Figure 13. The nano-sized specimens are prepared by Focused Ion Beam (FIB) and tested with a nano-indenter such as the Hysitron TriboIndenter TI $900^{[16]}$.

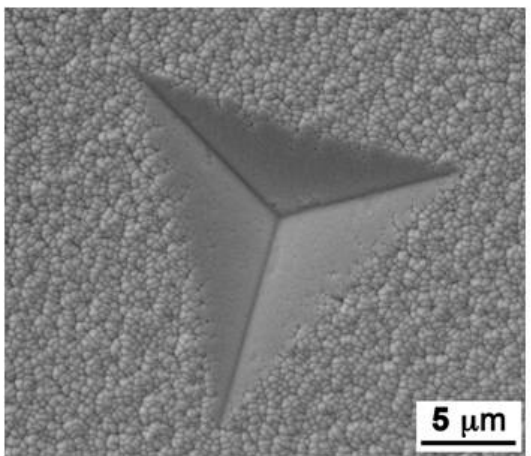

Indentation

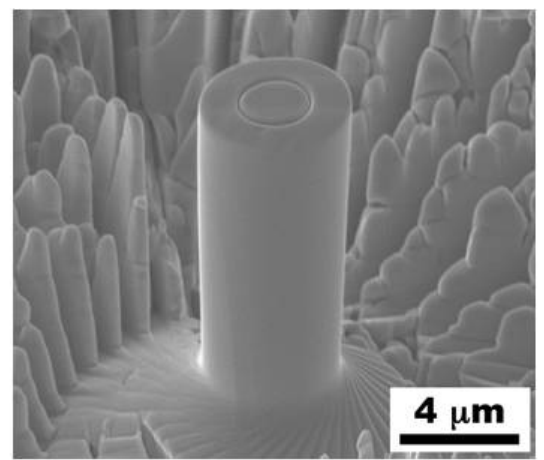

Pillar Compression

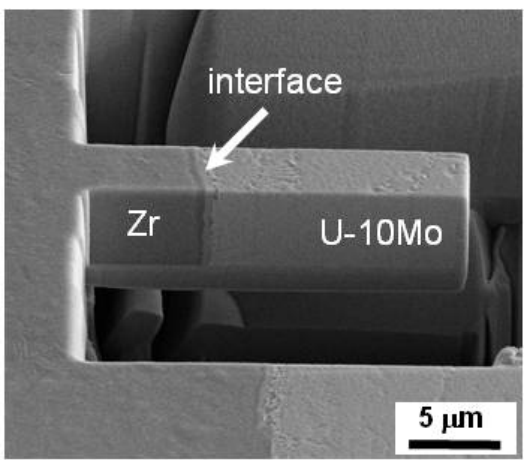

Cantilever Bend Test

Figure 13: Nano-Mechanical Test Samples (figure reference [16])

The installation of FIB equipment in the SSPA is not feasible due to footprint alone and is not further considered in this report. However, preparation of slightly larger micro-sized samples may be possible in the SSPA using the mini-mill discussed in section 3.1. These micro-sized specimens, particularly the cantilever bend test specimen, could be tested in the characterization cell of the SSPA with a micro-indenter such as a LECO LM series unit as seen in Figure 14. 


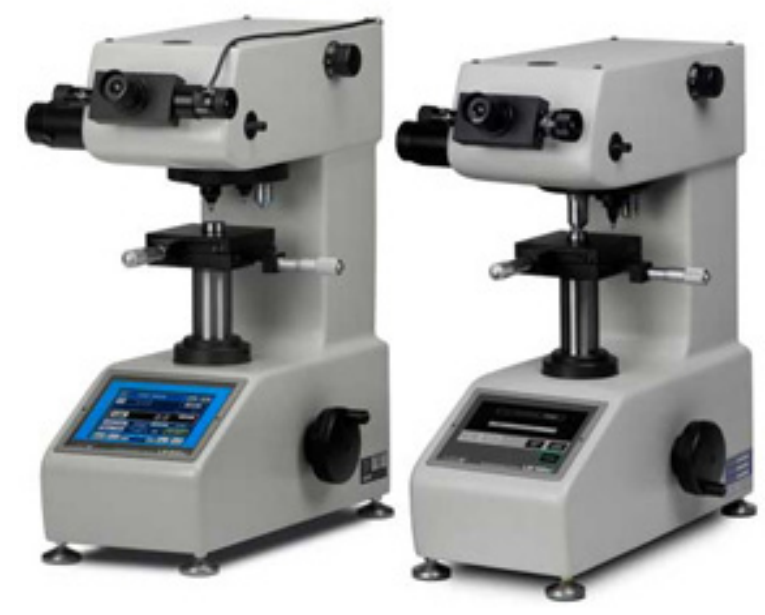

Figure 14: LECO LM Series Micro-Indenter (photo reference [17])

Modification feasibility is classified as Simple. A similar micro-indenter unit has already been modified for remote operation and is now in the HFEF.

Installation feasibility is classified as Difficult. Since the micro-indenter will likely be too large to pass through any port except the main window, installation will be performed through the main containment window of a potentially contaminated hot cell environment. Consequently, the installation feasibility is considered difficult unless the micro mechanical schedule could be accelerated to allow installation in the initial "clean" campaign. However, if the existing micro hardness tester at the HFEF is suitable for this testing, the installation of the equipment has already been accomplished (in this case the samples would most likely have to be produced at the SSPA and then transported back to the HFEF-adding time and increasing the likelihood of sample damage during transit).

Operation feasibility is classified as Difficult. This is considered difficult to perform due primarily to the complexity of sample preparation. Precise location of micro-cantilever specimens, without fracture during machining, is undemonstrated at this time. Production of samples suitable for this testing is foreseen to require the mini mill be operational in the sample preparation area.

\subsection{Fracture Mechanics}

Fracture mechanics methods are under development at INL and LANL and are proposed for use in a hot cell environment to quantify the cladding-to-foil bond toughness. Unlike previously discussed interfacial bond tests, fracture mechanics are a more direct method of bond quality measurement. In general, these test methods involve exacting sample preparations and testing of the specimen in a load frame in order to propagate a delamination (i.e. crack) across the cladding-to-foil interface. For the purposes of this report, several test methods are grouped into the "fracture mechanics" category. These tests include: 
- Dual Cantilever Beam Specimen (see Figure 15)

- $\quad$ Notched Bend Specimen (see Figure 16)

- Notch Shear Specimen (see Figure 17)

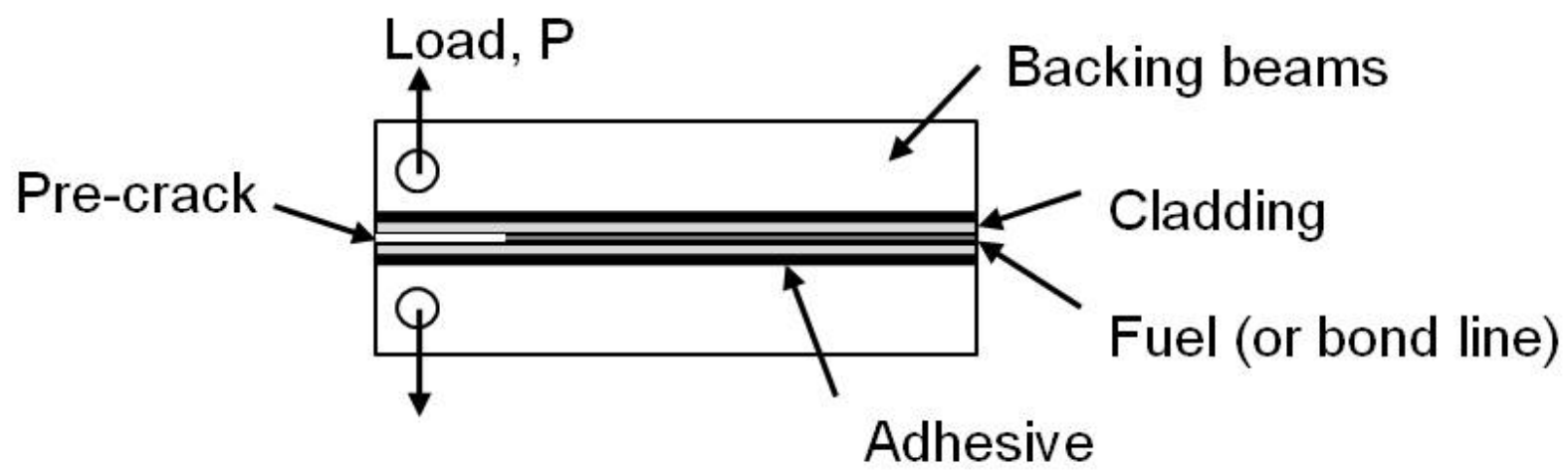

Figure 15: Dual Cantilever Beam Test Specimen (figure reference [13])

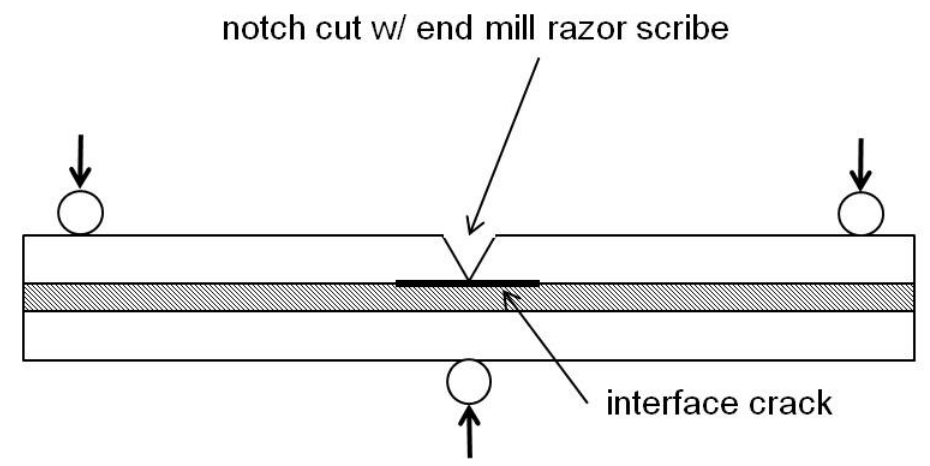

Figure 16: Notched Bend Specimen (figure reference [13])

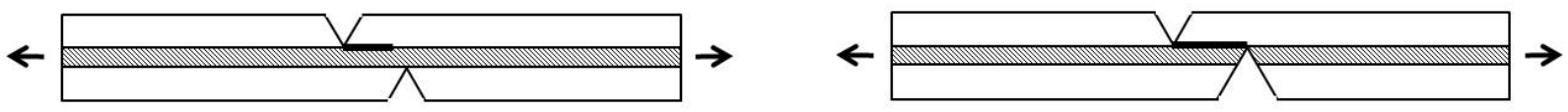

Figure 17: Notched Shear Specimens (figure reference [13])

Modification feasibility is classified as Moderate. A load frame is the primary apparatus for fracture mechanics testing. Although load frames are relatively straightforward devices and their remotization has been demonstrated for use in the HFEF, a suitable load frame small enough to fit into the SSPA's working area, and ideally to pass through the airlock or bagout ports, would likely be a custom design/fabrication effort. Mini load frame designs have been produced for use in similar sized chambers ${ }^{[18]}$. Alternatively, if this testing took place in the HFEF much of the actual test equipment would already exist and although the fabrication of the actual samples would require the mini mill which is addressed in section 3 of this report.

Installation feasibility is classified as Simple. Assuming that a suitable compact load frame design can be produced, installation of the equipment needed for fracture mechanics testing should be straightforward. Feedthroughs may include a few signal, controller, and power cables for operation of the load frame. 
Operation feasibility is classified as Difficult. The fracture mechanics work is considered difficult to perform due primarily to the complexity of sample preparation. Assumedly this work would be best performed in the more intimate sample preparation cell of the SSPA (which would require the mini mill be operational). In theory, preparation of the fracture samples could be performed using the resources in the HFEF, but as this resource is already backlogged with the existing scope and the planned equipment in the SSPA will be able to fabricate these better and faster this is the more desirable option.

\subsection{DSC}

A Differential Scanning Calorimeter (DSC) is intended to be used in the SSPA to quantify the specific heat capacity of irradiated specimens. A DSC, such as the Netzsch model DSC 404, pictured in Figure 18, can be purchased as an off-the-shelf unit and modified for remote use in the SSPA.

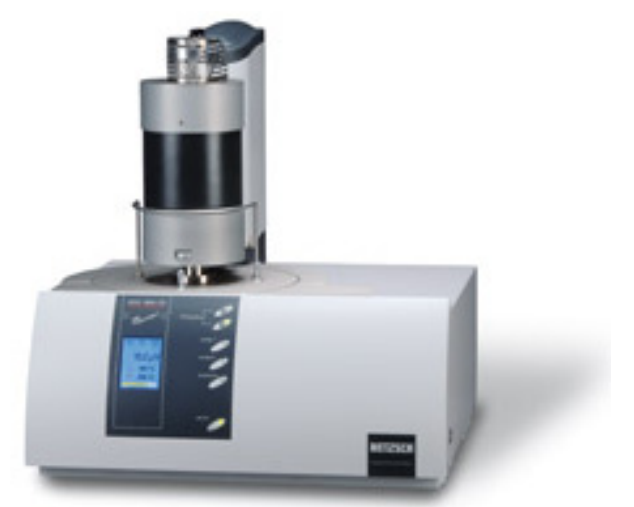

Figure 18: Example DSC Unit (photo reference [19])

Modification feasibility is classified as Difficult. No efforts to remotize a similar DSC are known at this time. While remotization of things like the control unit may turn out to be straightforward, design and fabrication of manipulator friendly features, which enable handling and loading of the delicate samples and sample holders, will likely be a labor intensive effort and may include several iterations.

Installation feasibility is classified as Difficult. The DSC unit will likely be difficult to install as it is too large to pass through any port except the main window. Since the modification of the DSC is likely to take a considerable amount of time, it will probably not be available until after the initial characterization cell installation campaign. Consequently, the evolution required to install the DSC will be performed through the main containment window of a potentially contaminated hot cell environment.

Operation feasibility is classified as Difficult. The DSC is a precision instrument which requires careful preparation of delicate samples. Loading of samples for testing requires careful placement. Additionally, sample holders, instrumentation, and other hardware can be slender and are often made from fragile materials. It should be expected that some of these items will be broken and require replacement during remote operations. 


\subsection{Dilatometer}

A dilatometer is intended to be used in the SSPA to quantify the coefficient of thermal expansion of irradiated specimens. A dilatometer, such as the Netzsch model DIL 402, pictured in Figure 19 , can be purchased as an off-the-shelf unit and modified for remote use in the SSPA.

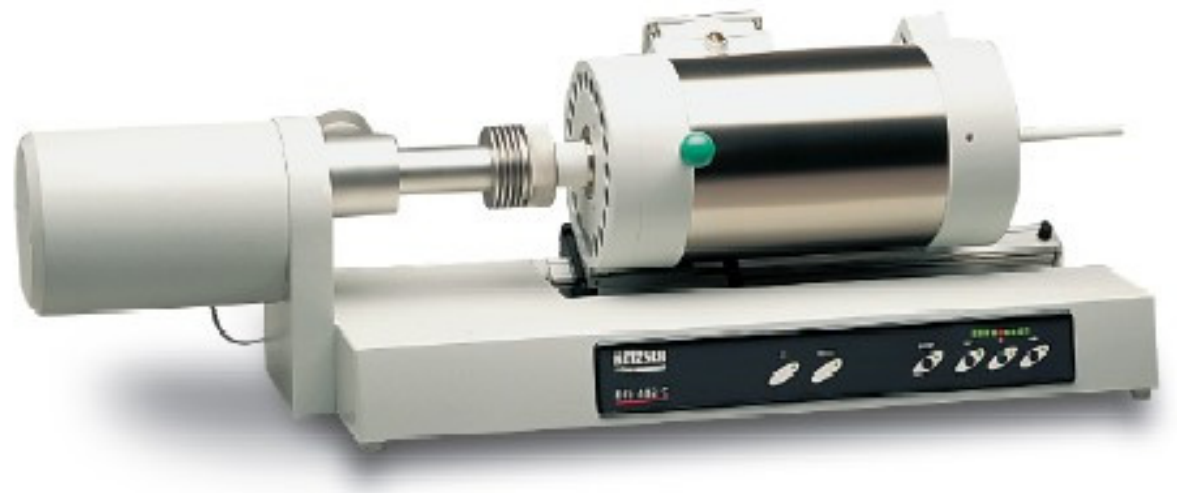

Figure 19: Example Dilatometer (photo reference [20])

Modification feasibility is classified as Difficult. Information regarding similar efforts to obtain thermal expansion data on irradiated fuel materials is scant. Like the DSC, design and fabrication of manipulator friendly features, which enable handling and loading of the delicate samples and sample holders, will likely be a labor intensive effort and may include several iterations.

Installation feasibility is classified as Difficult. Like the DSC, the dilatometer unit will likely be difficult to install as it is too large to pass through any port except the main window and will probably not be available until after the initial characterization cell installation campaign. Consequently, the evolution required to install the dilatometer will be performed through the main containment window of a potentially contaminated hot cell environment.

Operation feasibility is classified as Difficult. Like the DSC, the dilatometer is a precision instrument which requires careful preparation of delicate samples. Loading of samples for testing requires careful alignment. Additionally, sample holders, instrumentation, and other hardware can be slender and are often made from fragile materials. It should be expected that some of these items will be broken and require replacement during remote operations.

\section{Recommendations}

Based on the above the evaluations, some recommendations are provided:

While the mini-mill has the potential to bring substantial sample preparation and machining utility to the SSPA (and allow several of the proposed SSPA characterization activities to occur), it represents the largest "real estate" risk of all the SSPA sample preparation equipment. Consequently, it is recommended that efforts to remotize the existing mini-mill be commenced as soon as possible to enable design iteration and confidence in the final design. 
The saw, polisher, balance and blanking die should be obtained, modified/designed, and installed in time to accomplish the programmatic schedule.

Both the flash thermography and laser spallation techniques show a high level of feasibility as they are non contact forms of measurement that require little to no sample preparation. Additionally, both these techniques may be able to be employed at the same time. While it is unsure at this stage if the two could share the same optical path, they could conceivably share the same shielded plug installation.

It is recommended the further demonstration of the laser spallation method be pursued on fresh fuel at subcontracted facilities as soon as possible. Pending successful demonstration, the equipment necessary to perform laser spallation testing at the INL should be obtained in an expedient manner.

The bulge test method should be demonstrated on HIP bonded Aluminum clad specimens which are prepared via drilling of flat bottom holes before being pursed further as a prime candidate for the SSPA. At such a time the process could be reevaluated for inclusion in this equipment.

Successful sample preparation of micro-cantilever specimens should be demonstrated using mini-milling techniques (and evaluated to determine if this would translate to machining via remote handling). Successful demonstration should give way to further design and fabrication effort regarding in cell use of the technique. The viability of existing HFEF micro indenter testing capabilities should be also be further investigated.

Since there are no alternative methods to obtain heat capacity and thermal expansion data, it is recommended that DSC and dilatometer units be obtained as soon as possible to enable design iterations and give confidence in the final design (or a subcontract to have an outside vendor assess the feasibility). Adequate resources should be allocated for engineering and mock-up of these devices.

Ultimately, the decision on RERTR PIE characterization path forward will also include the advisability (and availability) of HFEF. It is beyond the scope of this document to evaluate the HFEF hot cell option in any kind of real comparison. It should be noted, however, that configuration change in HFEF has been both more expensive and taken a longer time than we anticipate will be the case for the SSPA.

\section{References}

[1] D.M. Wachs, "RERTR Fuel Development and Qualification Plan", rev 5, 07/05/2011, INL external report INL/EXT-05-01017.

[2] C. R. Clark et al., "Monolithic Fuel Plate Development at Argonne National Laboratory," RERTR 2003, 25th International Meeting on Reduced Enrichment for Research and Test Reactors (RERTR), October 5-10, 2003, Chicago, Il, U.S.A.

[3] A.B. Robinson et al., "Irradiation Performance of U-Mo Alloy Based 'Monolithic' Plate-Type Fuel - Design Selection”, INL external report INL/EXT-09-16807, Aug. 2009.

[4] TFR-700, "Technical and Functional Requirements for the EML Shielded Cells", rev 0, 07/28/2010. 
[5] Minitech Machinery Corporation website http://www.minitech.com/mill.php?step=Step+1, obtained 8-31-2011.

[6] Personal communication with J.W. Blaylock, Technician for HFEF Mock-Up Shop.

[7] IsoMet product brochure, http://www.buehler.com/productinfo/precision_saws/ isomet_low_speed.pdf, obtained 9-1-2011.

[8] MiniMet 1000 product brochure, http://www.buehler.com/productinfo/grinder_polishers/pdfs/ MiniMet1000.pdf, obtained 9-1-2011.

[9] Jared Wight, "Thermography as a Technique for Non-destructive Examination of Material Test Reactor Fuel Plates", 05/11/2009. Final paper for class PTTE 512, report transmitted to N.E. Woolstenhulme by J.M. Wight.

[10] FLIR SC4000, SC6000, SC8000 Series, product information website, http://www.flir.com/ thermography/americas/us/content/?id=18354

[11] R.B. Dinwiddie, "The Use of Microscopes and Telescopes in Thermography", presentation file "Microscopes and Telescopes.ppt", attachment to email B.L. Mackowiak to N.E. Woolstenhulme "Re: Reminder, Thermography", 6-20-11.

[12] D.E. Dombrowski to N.E. Woolstenhulme, email "RE: Figures", 9-19-11, attachment "Compact Tension (CT) Tests and Bulge Testing for Woolstenhulme.pptx"

[13] B.H. Rabin to N.E. Woolstenhulme, email "Re: Pics", 9-19-11, attachment "Rabin_Telecon_16Aug11.ppt"

[14] Eric Forrest, Cheng Liu, and Mann Lovato, preliminary results of adhesively bonded bulge test specimens, 8-11-11.

[15] INL Document LWP-14105, rev 1, "Pressure System Safety", 3-3-11.

[16] D.E. Dombrowski to N.E. Woolstenhulme, email "Fw: Photo of nanoindenter", 9-20-11, attachment "Nanoindenter figs.ppt"

[17] LECO LM-Series Product information webpage, http://www.leco.com/products/ hardness_testing/Micro_LM_series/LM_Series.html.

[18] Robert Rinefierd et al, "Design and Fabrication of a Miniature Tensile Load frame for a Scanning Electron Microscope", 5-14-2004, obtained from http://edge.rit.edu/content/OldEDGE/ public/Archives/P04004/PDR\%20Report.pdf on 9-19-2011.

[19] DSC 404 F3 Pegasus, Netzsch product information website, http://www.netzsch-thermalanalysis.com/us/products/detail/pid,45.html.

[20] DIL $402 \mathrm{C}$, Netzsch product information website, http://www.netzsch-thermalanalysis.com/us/products/detail/pid,16.html. 